\title{
Maternal Intrachromosomal Insertional Translocation Leads to Recurrent 1q21.3q23.3 Deletion in Two Siblings
}

\author{
Shane C. Quinonez, ${ }^{1}$ Peter Hedera, ${ }^{2}$ Mason Barr, ${ }^{3}$ Todd Ackley, ${ }^{1}$ Cindy Lam, ${ }^{4}$ Anjali Purkayastha, ${ }^{4}$ \\ Thomas W. Glover, ${ }^{1,5}$ and Jeffrey W. Innis ${ }^{1,5 *}$ \\ ${ }^{1}$ Division of Genetics, Department of Pediatrics, University of Michigan, Ann Arbor, Michigan \\ ${ }^{2}$ Division of Movement Disorders, Department of Neurology, Vanderbilt University, Nashville, Tennessee \\ ${ }^{3}$ Teratology Unit, Division of Genetics, Departments of Pediatrics, Pathology, and Obstetrics, University of Michigan, Ann Arbor, Michigan \\ ${ }^{4}$ Department of Pathology, The University of Michigan, Ann Arbor, Michigan \\ ${ }^{5}$ Department of Human Genetics, The University of Michigan, Ann Arbor, Michigan
}

Manuscript Received: 9 May 2012; Manuscript Accepted: 17 June 2012

We identified a novel $6.33 \mathrm{Mb}$ deletion of 1q21.3q23.3 (hg18; chr1: 153035245-159367106) in two siblings presenting with blepharophimosis, ptosis, microbrachycephaly, severe psychomotor, and intellectual disability. Additional common features include small corpus callosum, normal birth length and head circumference, postnatal growth restriction, low anterior hairline, upturned nose, bilateral preauricular pits, widely spaced teeth, gingival hypertrophy, left ventricular dilatation with decreased biventricular systolic function, delayed bone age, 5th finger clinodactyly, short 3rd digit, hyperconvex nails, obstructive and central sleep apnea, and bilateral heel contractures. Fluorescence in situ hybridization (FISH) performed in the mother of both children showed an apparently balanced, intrachromosomal insertional translocation of $1 \mathrm{q} 21.3 \mathrm{q} 23.3$ to 1q42.12. The sibling recurrence likely arose by a maternal meiotic crossing over on the rearranged chromosome 1 between the deleted region and the insertion. We hypothesize that the decreased cardiac function and contractures may be related to LMNA haploinsufficiency. This case illustrates the importance of FISH when attempting to determine inheritance of a copynumber variation and emphasize the value of evaluating known haploinsufficiency phenotypes for genes in deleted regions.

(C) 2012 Wiley Periodicals, Inc.

Key words: blepharophimosis; developmental delay; chromosome 1q deletion; Ohdo-like syndrome; BMR syndrome

\section{INTRODUCTION}

The use of array-comparative genomic hybridization (CGH) has allowed clinicians to detect pathogenic copy number losses and gains with ever increasing sensitivity. Abnormal results require further laboratory investigation not only for confirmation purposes, but also to investigate whether the genomic gain or loss occurred de novo or was the result of a parental chromosomal
How to Cite this Article:

Quinonez SC, Hedera P, Barr M, Ackley T, Lam C, Purkayastha A, Glover TW, Innis JW.

2012. Maternal intrachromosomal insertional translocation leads to recurrent 1q21.3q23.3 deletion in two siblings.

Am J Med Genet Part A 158A:2591-2601.

abnormality. Fluorescence in situ hybridization (FISH) may provide critical information about parental balanced insertional translocations or other chromosomal rearrangements that may otherwise be missed and can impact recurrence risk significantly. Insertional translocations can be: (a) simple intrachromosomal or interchromosomal insertional translocations or (b) complex insertional translocations [Kang et al., 2010]. Nowakowska et al. [2011] found that $2.1 \%$ of array abnormalities were the consequence of a parental balanced insertional translocation. This may be an underestimate since not all parents were available for evaluation in their study and very small array abnormalities were not fully evaluated given the limitations of FISH. However, this supports the importance of FISH confirmation when faced with an array abnormality.

There are multiple patients described in the literature with deletions that include part or all of 1q21-q23 [Estevez de Pablo et al., 1980; Schinzel and Schmid, 1980; Moghe et al., 1981; Martin and Simpson, 1982; Taysi et al., 1982; Silengo et al., 1984; Beemer

${ }^{\star}$ Correspondence to:

Jeffrey W. Innis, M.D., Ph.D., Department of Human Genetics, 4811 Med Sci. II, 1241 E. Catherine St., Ann Arbor, MI 48109-5618.

E-mail: innis@umich.edu

Article first published online in Wiley Online Library

(wileyonlinelibrary.com): 17 August 2012

DOI 10.1002/ajmg.a.35563 
et al., 1985; Franco et al., 1991; Leichtman et al., 1993; Lo et al., 1993; Melis et al., 1998; Waggoner et al., 1999; Pallotta et al., 2001; Monica et al., 2007; Reddy et al., 2009]. Variable sizes and deletion endpoints on 1q21-q23 give rise to a wide variety of clinical problems.

We present a male propositus and his female sibling with highly similar features including blepharophimosis, ptosis, developmental intellectual disability, postnatal growth restriction, numerous dysmorphic features, obstructive/central sleep apnea, and seizures. Initial karyotypes performed prior to the advent of chromosomal microarrays showed normal G-banded results. Re-evaluation of these children with chromosomal microarray studies showed a 6.33 Mb loss of chromosome 1q21.3q23.3 (hg18; chr1: 153035245 -159367106) in both children, that resulted from the unbalanced product inherited from a maternal insertional translocation. We describe the clinical, cytogenetic, and molecular features of these siblings, and we compare their phenotypes to deletion 1q21-q23 cases in the literature.

\section{MATERIALS AND METHODS}

Research was approved by the Institutional Review Board for Human Subject Research at the University of Michigan. Informed consent was obtained from the family. Chromosomal microarray analyses were conducted in the Michigan Medical Genetics Laboratories (MMGL) at the University of Michigan using two oligonucleotide-based array platforms with whole genome coverage: a custom-designed EMArray Cyto6000 chip, implemented on the Agilent $44 \mathrm{~K}$ platform [Baldwin et al., 2008], which originally identified a $6.5 \mathrm{Mb}$ deletion, and the Agilent human genome G4411B 244K array platform (Agilent Technologies Inc., Santa Clara, CA) to refine the boundaries of the deletion interval to 6.33 $\mathrm{Mb}$ (the latter is shown in Fig. 2). The procedures for DNA digestion, labeling, and $\mathrm{CGH}$ were as described in Agilent oligonucleotide-based array CGH for genomic DNA analysis, Protocol version 4.0 June 2006 (Agilent Technologies, Inc.) with some modifications [Baldwin et al., 2008]. The fluorescent signals on the array slides were detected and scanned into image files using the GenePix 4200A scanner and GenePix-Pro 6.1 software (Axon Instruments/Molecular Devices Corp., Union City, CA). The array images were imported and converted for display by Agilent Feature Extraction 9.5 software. Data were analyzed by Agilent's CGH Analytics 3.5 software to determine copy number variation between experimental DNA and a sex mismatched control DNA preparation. Numbering of the Cyto6000 44K EMArray and 244K Agilent array results utilized the UCSC hg18 (Build 36.1, March 2006) assembly. The resultant data were extracted using Feature Extraction software, version 9.5.1.1, and analyzed and plotted using CGH Analytics version 3.5.14 or DNA analytics version 4.0.81 (both from Agilent Technologies) using ADM-1 algorithm with a sensitivity threshold of 6.7 (for Agilent 244k arrays the settings are ADM-2 algorithm with a sensitivity threshold of 6.0). Gains and losses were called according to interpretation criteria established by the International Standard Cytogenomic Array (ISCA) Consortium, as described in Baldwin et al. [2008]. The resulting $\log 2$ derivatives of the patient:control signal intensity ratios were plotted relative to the genomic location of the corresponding probes. For detection of gains or losses the thresholds for the $\log 2$ ratios were set at -0.32 for losses and 0.26 for gains. A minimum of four contiguous oligonucleotide probes showing loss or gain of signal intensity was required to make an aberration call. The deletion was verified in the patients using BAC probe RP11-101J8 (Bluegnome, Cambridge, UK) in metaphase FISH. This same probe was used for parental FISH analysis. To determine the orientation of the insertion in the maternal chromosome 1, an additional BAC RP11-307C12 probe (Bluegnome), mapping within the deleted region, was used. Metaphase FISH was performed by standard methods in the University of Michigan Clinical Cytogenetics Laboratory.

\section{CLINICAL REPORT}

Patient 1 was the product of an uncomplicated first pregnancy to a 29-year-old woman whose prenatal ultrasounds exams were normal. He was born at 41 weeks gestation via cesarean due to failure to progress. At birth, weight, occipitofrontal head circumference (OFC), and length were at the 28th, 25th, and 25th centiles, respectively. Dysmorphic features observed at birth included: bilateral preauricular pits, low set and small ears which measured $3.0 \mathrm{~cm}$ (right; $-3.5 \mathrm{SD}$ ) and $3.2 \mathrm{~cm}$ (left; $-3.5 \mathrm{SD}$ ), overfolded helices, wide nasal bridge with an inner canthal distance of $2.5 \mathrm{~cm}$ $(+2 \mathrm{SD})$, short palpebral fissures of $1.4 \mathrm{~cm}(-3 \mathrm{SD})$, bulbous nose with nasal septum extending below the nasal alae, right eyelid ptosis, and retrognathia. Figure 1 shows facial features of Patient 1 at 7, 9, and 16 years of age. Echocardiogram showed a secundum atrial septal defect (ASD) and apical muscular ventricular septal defect (VSD), a dilated left ventricle, and patent ductus arteriosus (PDA), which was closed by coil occlusion at 17 months of age; ASD and VSD, closed spontaneously. Bilateral inguinal hernias were surgically corrected on day of life 2 by herniorrhaphy. A persistent undescended right testicle was surgically corrected by orchiopexy at 2 years of age. A gastric feeding tube and Thal fundoplication were performed at 6 months of age. At 16 months of age, his weight, OFC, and height were $9.9 \mathrm{~kg}$ (11th centile), $45 \mathrm{~cm}$ (3rd centile), and $70.5 \mathrm{~cm}$ (<3rd centile; 50th centile for an 11-month-old), respectively. Exam showed bilateral blepharophimosis and ptosis. At 16 months he began sitting unsupported, pulling to stand briefly with the assistance of furniture and began rolling over in both directions. Radiographic evaluation at 16 months showed a bone age of 1 year; radiographs also showed mild shortening of the middle phalanges of the 5th fingers, consistent with bilateral clinodactyly. At 35 months of age he began cruising and following simple commands but had not developed a pincer grasp.

The patient developed tonic seizures twice at 3.5 years of age. Brain magnetic resonance imaging (MRI) indicated the presence of a small corpus callosum and a small volume brain stem. Brain computed tomography (CT) showed microcephaly with lowdensity white matter. Gray matter irregularities were also noted with increased gyrations present consistent with possible heterotopia and cortical dysplasia. Electroencephalogram (EEG) showed left frontal central epileptiform activity with mild diffuse neuronal dysfunction. He was treated for only 1.5 months with the anticonvulsant Phenytoin (Dilantin), after which it was discontinued. He subsequently experienced two seizures at 8 years of age with an EEG showing multifocal spikes and background slowing. He was treated with the anticonvulsant Levetiracetam (Keppra) from 8 to 

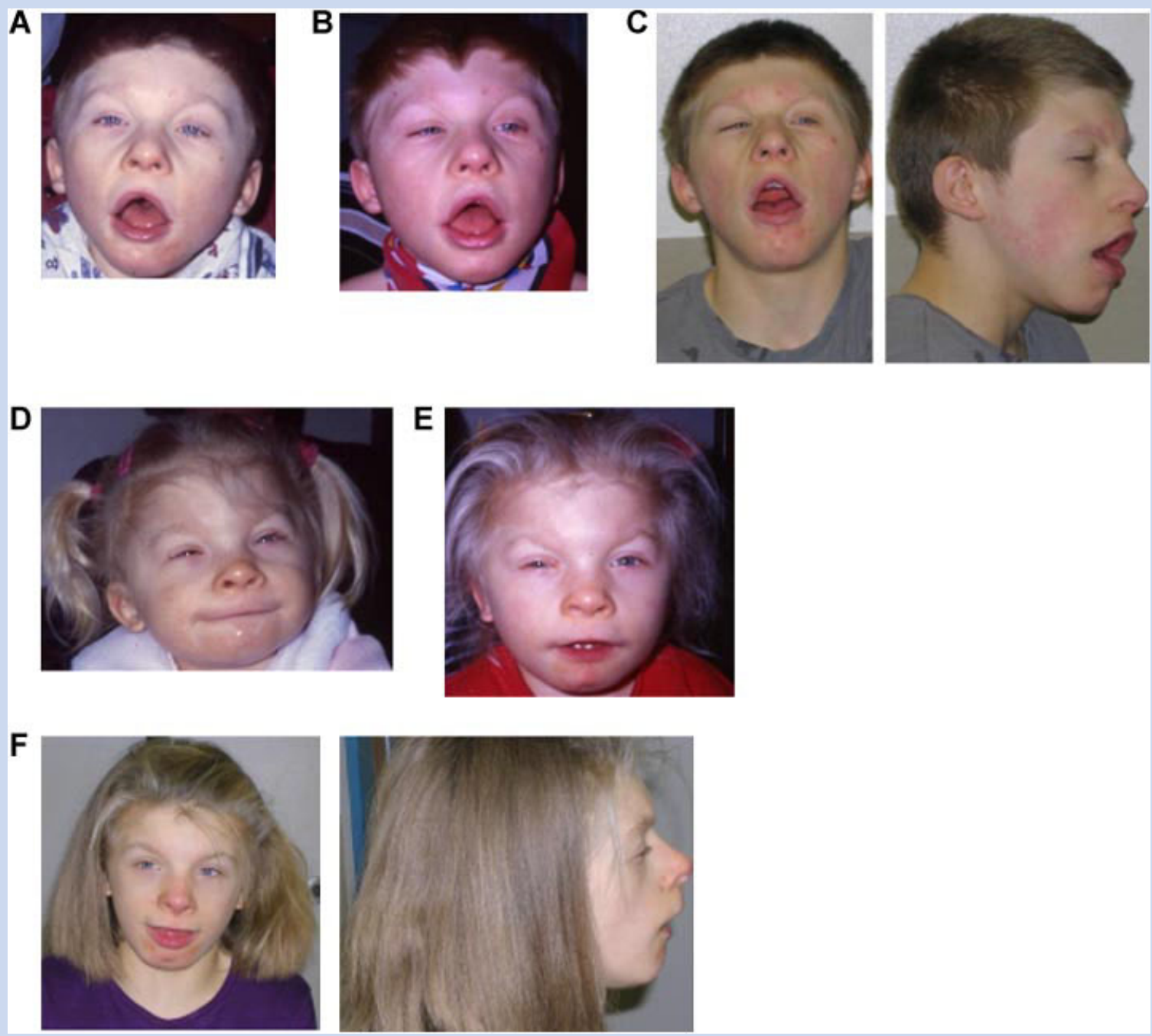

FIG. 1. Facial features of male at $[A]>$ years of age, $(B) 9$ years, and $(C) 16$ years. Facial features of female at $[D] 2$ years of age, $[E] 4$ years, and $[F] 9$ years. Note low anterior hairline, blepharophimosis, low set ears, corpuscular lobules, upturned nose, and thin vermillion border.

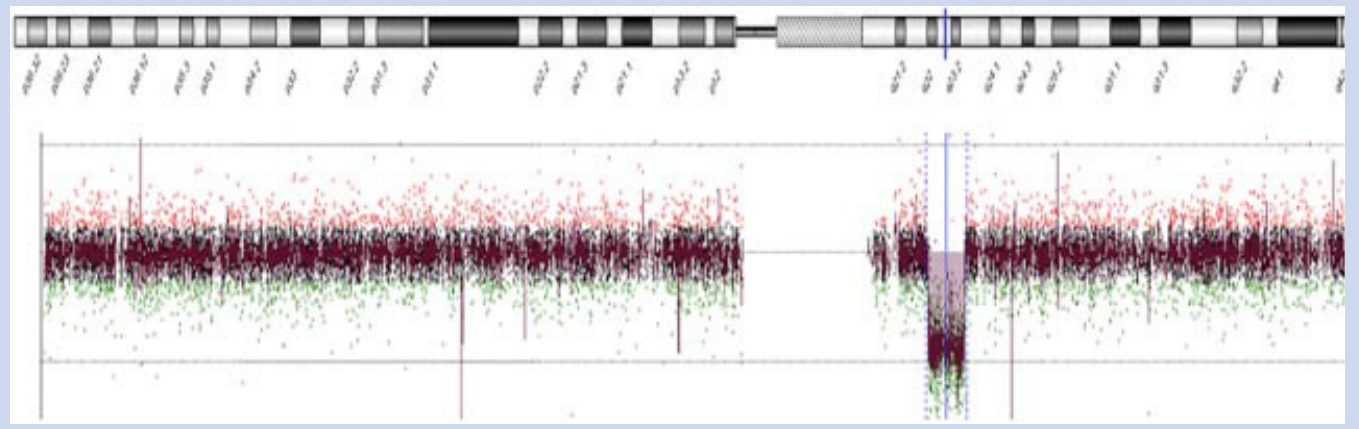

FIG. 2. Chromosomal microarray (CMA) results detailing a $6.33 \mathrm{Mb}$ deletion on chromosome 1 q21.3q23.3 (hg18; chr1: 153035245-159367106). 
10 years of age and then weaned off of all anti-epileptic medication, with no further seizures to date. He ambulated with assistance at 7 years of age. At 7 years, all growth centiles were $<5$ th centile, sleep studies showed both obstructive and central apneas, which improved with oxygen supplementation, and a trial of continuous positive airway pressure (CPAP) was unsuccessful. Increased tone was noted in his lower extremities at 8 years.

At 16 years of age he was walking independently and following simple commands, yet he had no expressive language. His weight, OFC, and height were $37.9 \mathrm{~kg}(-3 \mathrm{SD}), 51.7 \mathrm{~cm}$ (<3rd centile; 50 th centile for a 4-year-old), and $130 \mathrm{~cm}$ ( $<3 \mathrm{rd}$ centile; 50th centile for 8-year-old), respectively. His ears were normally set and measure $5.7 \mathrm{~cm}$ (left; $-1 \mathrm{SD}$ ) and $5.4 \mathrm{~cm}$ (right; $-1.5 \mathrm{SD}$ ). Eye exam demonstrated an interpupillary distance of $5.5 \mathrm{~cm}$ (25th centile), inner canthal length of $3.2 \mathrm{~cm}$ (50th centile), and an outer canthal distance of $8.0 \mathrm{~cm}$ (10th centile). Palpebral fissures measured $2.4 \mathrm{~cm}$ (left; $-5 \mathrm{SD}$ ) and $2.3 \mathrm{~cm}$ (right; $-5 \mathrm{SD}$ ). He had slightly arched eyebrows, a flat philtrum of normal length, a tented upper lip, widely spaced teeth, and prominent gingival hypertrophy. $\mathrm{He}$ drooled persistently. Extremity exam showed limitation of extension and supination of his arms bilaterally. His left palm measured $10.5 \mathrm{~cm}$ (30th centile) with total hand length of $17.0 \mathrm{~cm}(15 \mathrm{th}$ centile). His right palm measured $10.5 \mathrm{~cm}$ (30th centile) with a total hand length of $17.2 \mathrm{~cm}$ (20th centile). Middle finger lengths measured $6.5 \mathrm{~cm}$ (left; $<3$ rd centile, $\sim 50$ th centile for 9.5-year-old) and $6.7 \mathrm{~cm}$ ( right; $<3$ rd centile, $\sim 50$ th centile for 10-year-old). Bilateral 2nd toenails and right 5 th toenail were hyperconvex. Toes were short with bilateral distal valgus positioning of the 1 st toe. The feet measured $22.3 \mathrm{~cm}$ (left; $-3 \mathrm{SD}$ ) and $21.5 \mathrm{~cm}$ (right; $-4 \mathrm{SD}$ ). The patient walked with both hips and knees flexed. He had bilateral heel contractures, treated with ankle-foot orthoses, limitation of full knee extension, and a $37^{\circ}$ curvature of the lumbar-thoracic to low lumbar spine on radiographs.

Recent cardiac evaluation and echocardiography at 17 years of age showed Patient 1 to have mildly diminished right ventricular and mild-moderately diminished left ventricular systolic function with mild dilation of the left ventricle $(Z$-score +2.5$)$. Electrocardiographic evaluation, including Holter monitoring, showed no conduction abnormalities. Given the decreased systolic function Patient 1 was started on Enalapril (Vasotec) for afterload reduction.

Following the birth of Patient 1 the mother experienced two spontaneous miscarriages at 17 weeks gestation and between 14 and 15 weeks gestation. Fetal autopsy of the latter showed no major malformations and the cause of the demise was not identified.

Patient 2 is the younger female sibling of Patient 1. The pregnancy was complicated by intrauterine growth restriction and premature and prolonged rupture of membranes. The patient was born at 35 weeks gestation via vaginal delivery. Upon delivery, Apgar scores were 3, 6, and 9 at 1, 5, and $10 \mathrm{~min}$, respectively. At birth, her weight, OFC and length were at the 3rd, 30th, and 5th centiles, respectively. Figure 1 shows facial features of Patient 2 at 2 , 4 , and 9 years of age. She remained in the neonatal intensive care unit for 15 days secondary to preterm delivery and hyperbilirubinemia (maximum of $9.1 \mathrm{mg} / \mathrm{dl}$ ) that was treated successfully with phototherapy. She was also diagnosed with transient thrombocytopenia requiring 1 platelet transfusion. The patient's growth centiles progressively fell during infancy. The patient began using oxygen supplementation between 3 and 4 months of age following a viral infection. Since then, she has continued with nighttime oxygen via nasal cannula with sleep studies showing obstructive and central apneas, which improved on oxygen. Like her brother, a trial of CPAP was unsuccessful. At 6 months of age she required gastrostomy tube placement and Nissen fundoplication due to poor weight gain and gastroesophageal reflux. She had severe global developmental delay, sitting at 15 months of age but unable to roll over. Dysmorphic facial features include microcephaly, prominent metopic ridge, blepharophimosis, upturned nose, bilaterally overfolded and thickened helices and high palate. The patient experienced a generalized tonic-clonic seizure at 2 years. EEG at that time showed left frontal lobe hyperactivity. No other seizures have been recorded. Brain MRI showed mildly diminutive corpus callosum and Arnold-Chiari malformation with cerebellar tonsils extending 6-7 mm below the foramen magnum. Increased tone was noted in the lower extremities.

At 11 years of age, she walked independently and followed simple commands but had no expressive language. Her weight was $26.4 \mathrm{~kg}$ ( 1 st centile) and head circumference was $47.6 \mathrm{~cm}(<3 \mathrm{rd}$ centile, $-4 \mathrm{SD})$. She had not yet entered puberty. She had coarse golden-brown hair, a low anterior hairline, and preauricular pits bilaterally. Her ears measured $5.0 \mathrm{~cm}$ (left; $-2.5 \mathrm{SD}$ ) and $4.8 \mathrm{~cm}$ (right; $-2.5 \mathrm{SD}$ ) and they were normally set. She had blepharophimosis and ptosis. Her interpupillary distance measured $5.4 \mathrm{~cm}$ (50th centile); inner canthal distance was $3.3 \mathrm{~cm}(+1 \mathrm{SD})$; outer canthal distance was $7.8 \mathrm{~cm}(-1.5 \mathrm{SD})$ and palpebral fissures measured $2.2 \mathrm{~cm}$ (left; $-5 \mathrm{SD}$ ) and $2.0 \mathrm{~cm}$ (right; $-5 \mathrm{SD}$ ). She had anteverted nares, a flattened philtrum, thin upper lip vermillion, gingival hypertrophy, and widely spaced teeth. She had normal range of motion of the upper extremities. Her left palm measured $9.0 \mathrm{~cm}$ (45th centile) with a total left hand length of $15.2 \mathrm{~cm}(25 \mathrm{th}$ centile). The right palm measured $8.7 \mathrm{~cm}$ (35th centile) with a total right hand length of $15 \mathrm{~cm}$ (15th centile). Middle finger lengths measured $6.2 \mathrm{~cm}$ (left; 15 th centile) and $6.3 \mathrm{~cm}$ (right; 20th centile). She had hyperconvex 2 nd and 5th toenails bilaterally, and bilateral 5 th finger clinodactyly. Her left foot measured $18.0 \mathrm{~cm}(-4 \mathrm{SD})$ and right foot was $19.5 \mathrm{~cm}(-3 \mathrm{SD})$. She had bilateral heel contractures treated with ankle-foot orthoses.

At 12 years of age Patient 2 underwent formal cardiology evaluation. Echocardiography showed mildly diminished right and left ventricular systolic function as well as a mildly dilated left ventricle $(Z$-score +2.3$)$. Electrocardiogram showed a first degree atrio-ventricular (AV) block confirmed by Holter monitoring showing as well an isolated sinus node exit block with occasional junctional escape. Given the diminished systolic function Patient 2 was placed on Enalapril (Vasotec) for afterload reduction.

\section{RESULTS}

Both siblings had normal peripheral blood G-banded karyotypes and normal subtelomeric FISH analysis. Because Patient 1 had features similar to blepharophimosis, ptosis, and epicanthus inversus syndrome (BPES; OMIM 110100) we performed FOXL2 DNA sequencing and FISH for a $3 \mathrm{q} 23$ microdeletion at the FOXL2 locus given that $12 \%$ of patients with BPES have a deletion of FOXL2 [Beysen et al., 2009; D’haene et al., 2010]. Both studies were normal 
in Patient 1. A maternal blood karyotype performed in 1997 showed a probable paracentric inversion 46,XX,inv(1)(q42.11q42.3), which was not studied further. Combined microarray and FISH analyses of new maternal samples obtained because of the discovery of deletions in her offspring, showed this instead to be an intrachromosomal insertional translocation involving chromosome 1. Both siblings showed a $6.33 \mathrm{Mb}$ single copy deletion of 1q21.3q23.3 by chromosomal microarray (CMA; Fig. 2), which was confirmed by metaphase FISH with BAC probe RP11-101J8 (Fig. 3). Parental FISH analysis with probe RP11-101J8 showed normal paternal studies and an insertion of $1 \mathrm{q} 21.2 \mathrm{q} 23.3$ material at $1 \mathrm{q} 42.12$ on one maternal chromosome 1 homologue. The insertion was determined to be direct (same orientation), by FISH using BAC probes RP11-101J8 and RP11-307C12, which map within the inserted region. Maternal peripheral blood CMA (Agilent, 244K) was normal indicating that, at the resolution of the CMA used, the insertion appears balanced. Figure 3 shows the results of FISH studies for the mother and Patient 2 . These results suggest that the occurrence of $\operatorname{del}(1)(\mathrm{q} 21.3 \mathrm{q} 23.3)$ in both siblings likely occurred via recurrent maternal meiotic crossing over between 1q21.3q23.3 and the insertional translocation at $1 \mathrm{q} 42$.

\section{DISCUSSION}

We describe two siblings with a unique combination of features associated with a $6.33 \mathrm{Mb}$ deletion of 1q21.3q23.3 (hg18; chr1: 153035245-159367106). The major features shared by them include severe intellectual disability, normal birth length and head circumference, postnatal growth restriction, microbrachycephaly, blepharophimosis, ptosis, upturned nose, bilateral preauricular pits, widely spaced teeth, gingival hypertrophy, left ventricular dilatation with decreased biventricular systolic function, delayed bone age, 5th finger clinodactyly, short 3rd digit, heel contractures, short feet, and hyperconvex nails. Both patients also exhibit central and obstructive sleep apnea, requiring oxygen therapy, and seizures with brain imaging showing a small corpus callosum. Congenital heart defects (ASD, VSD, and PDA) were seen only in Patient 1.

The deletions in Patients 1 and 2 resulted from inheritance of a meiotic recombination product involving a maternal chromosome carrying an apparently balanced insertion of $6.33 \mathrm{Mb}$ of material from 1q21.3q23.3 inserted into 1q42.12. Maternal meiotic recombination likely occurred between the deletion and insertion sites on

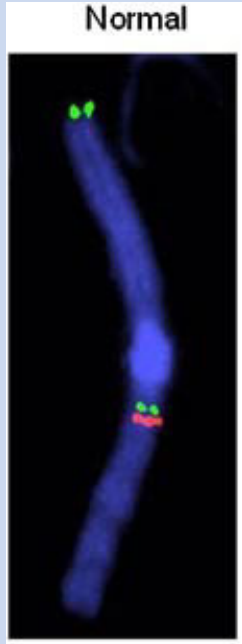

Chromosome 1
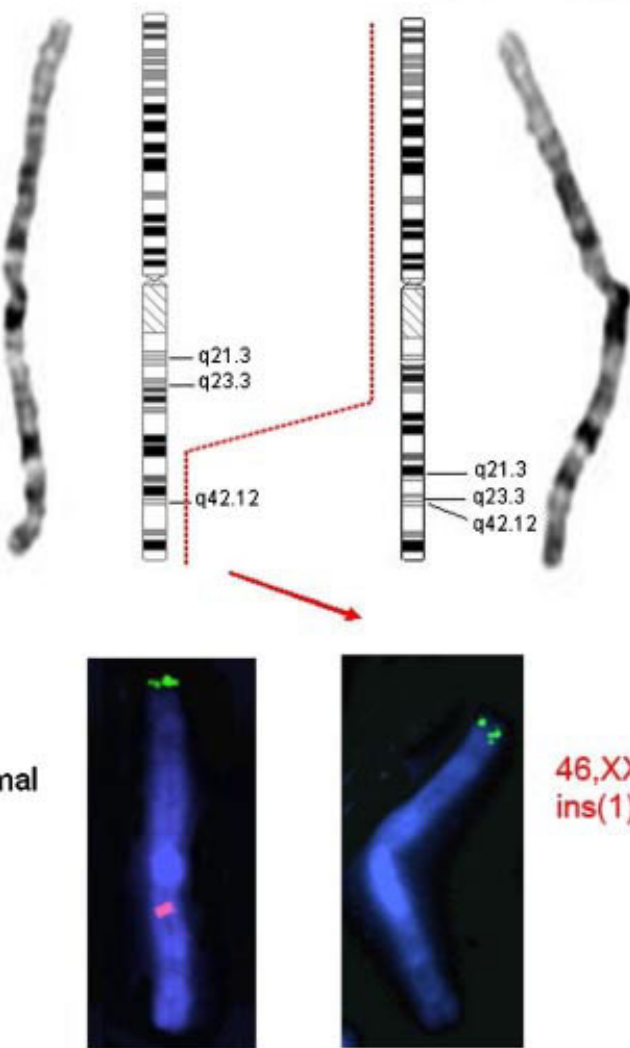

\section{$46, X X$, ins $(1)(q 42.12 q 21.3 q 23.3)$}

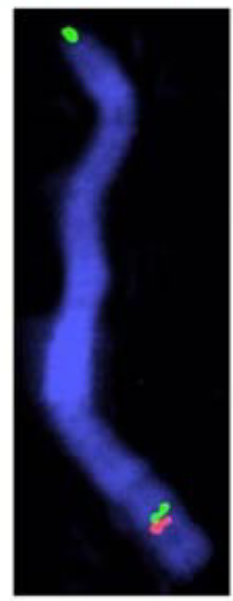

$46, X X, \operatorname{rec}(1) \operatorname{del}(1)(q 21.3 q 23.3)$ ins(1)(q42.12q21.3q23.3)mat

FIG. 3. Chromosome 1 metaphase FISH studies in mother [top] showing normal and insertional translocation chromosomes, and normal and recombinant chromosome (with deletion) in daughter (bottom). Control chr1 telomeric BAC probe (green telomeric signal), and BAC probes for 1q21.3q23.3 (green and red interstitial signals, RP11-101J8 and RP11-307C12, which allowed for assessment of directionality of the insertion). 
$\frac{\text { ङ }}{\frac{\pi}{0}}$

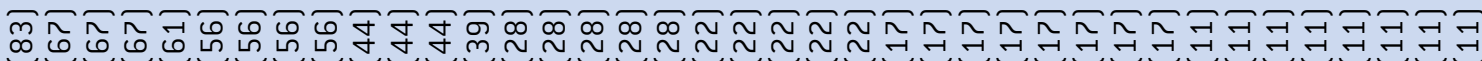

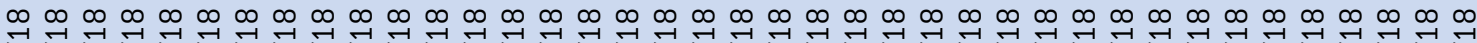

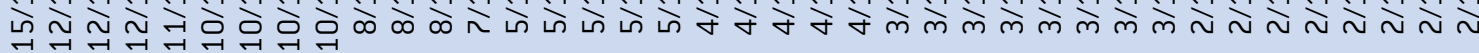

$\sim$

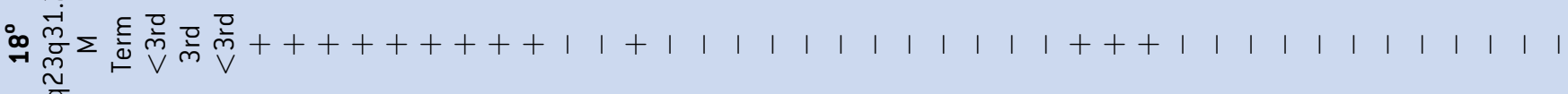

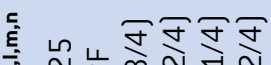

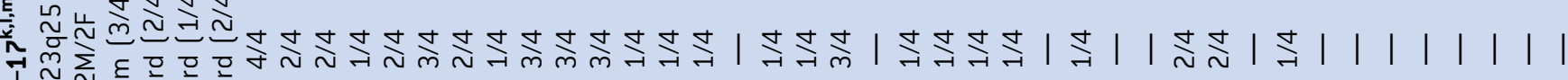

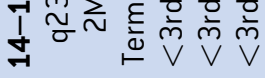

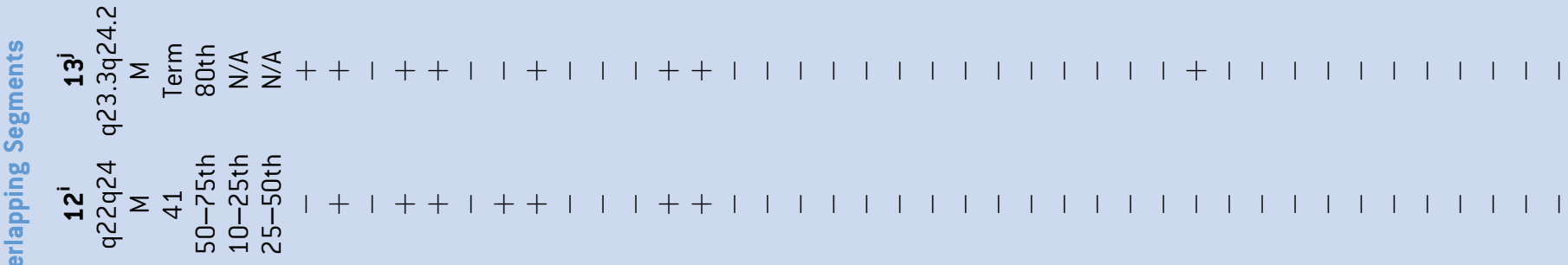

io in $\cong \cong 刃$

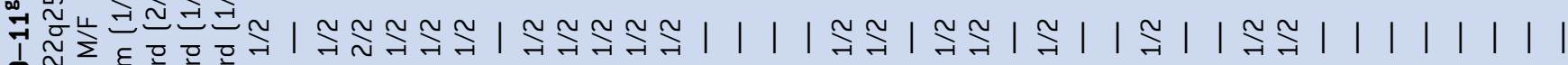

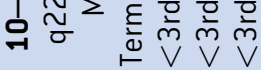

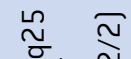

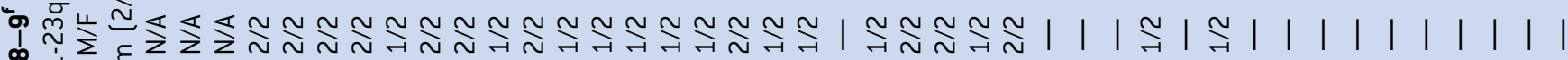
$\stackrel{0}{\stackrel{1}{\sigma}} \stackrel{\frac{\varepsilon}{\omega}}{\models}$

in $\pi \overparen{m} \overparen{m}$

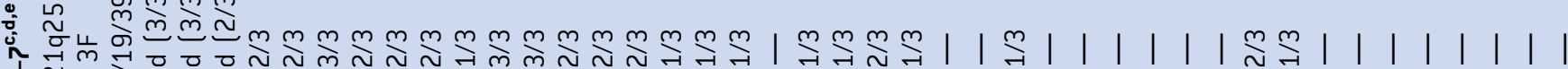

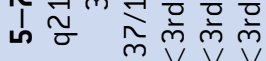

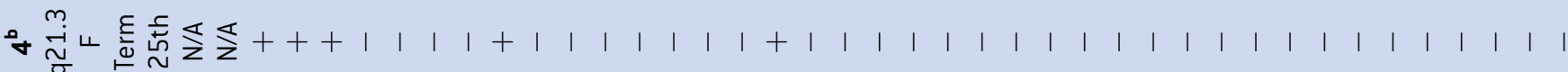

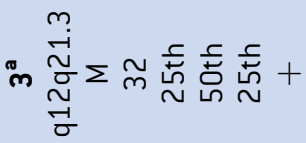

$\sim \stackrel{m}{\sim}$

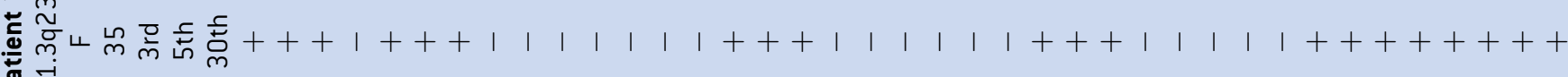
i $\underset{\sigma}{\stackrel{1}{\sigma}}$

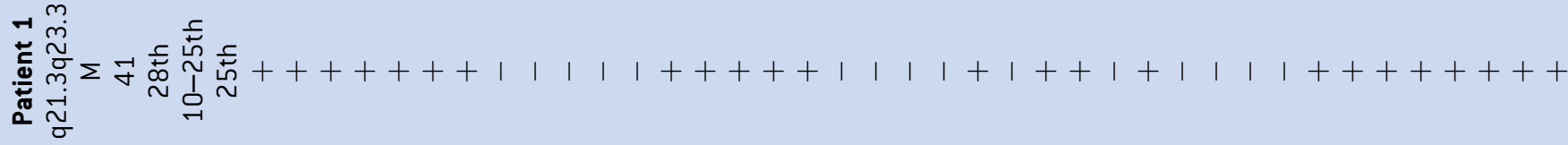
芩

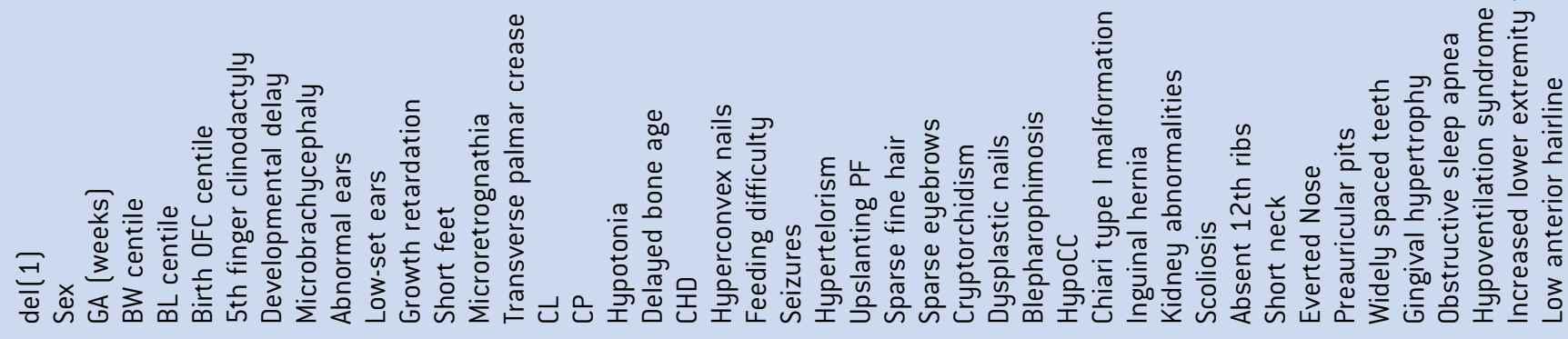




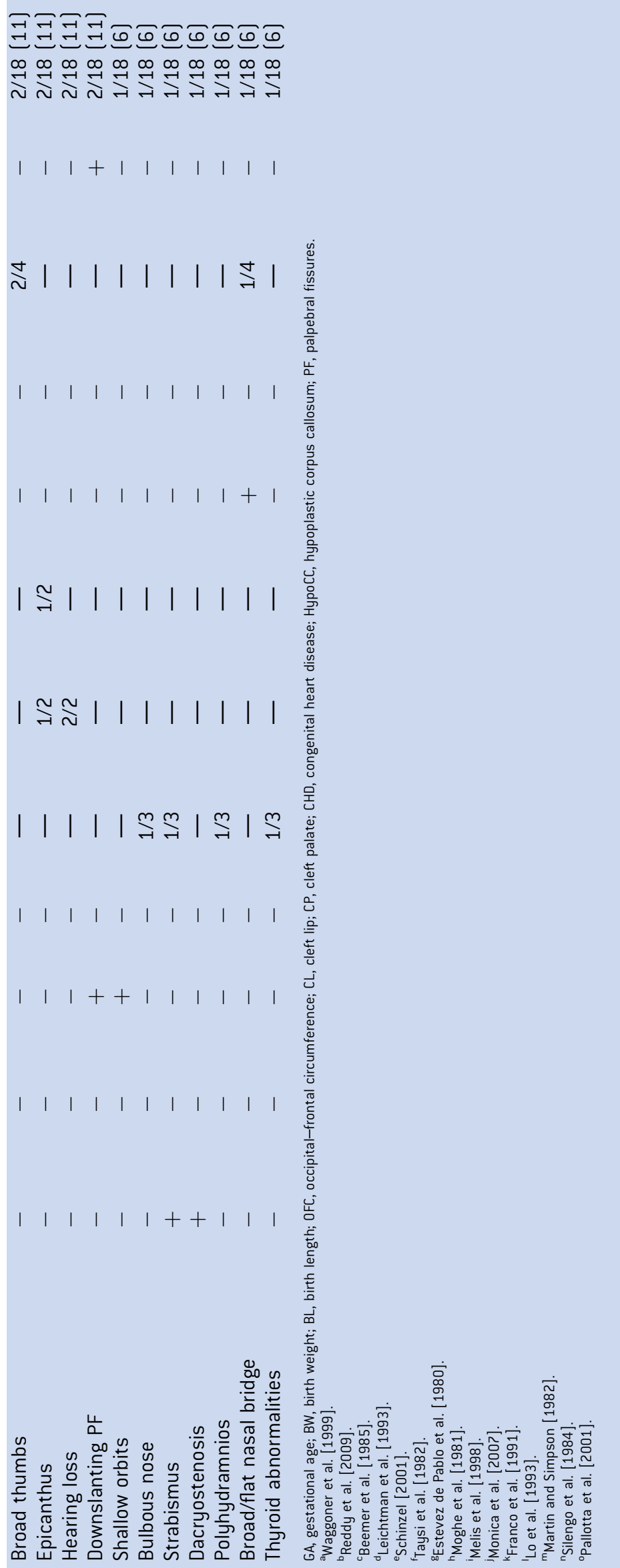

1q in both children, leading to deletion of 1q21.3q23.3 in the two children. Nowakowska et al. [2011] reported 10 cases with array abnormalities caused by parental apparently balanced insertional translocations. In all 10 cases, similar to ours, array-CGH analysis showed haploinsufficiency in the patients, which were all confirmed by FISH analysis although subsequent parental FISH studies determined that the imbalances were inherited from a parent carrying an apparently balanced insertion. These cases highlight the need for FISH analysis of what may appear to be losses or gains detected by array analysis, especially in cases where family recurrence is observed.

There have been multiple patients described in the literature with deletions that include part or all of the $6.33 \mathrm{Mb}$ loss in our patients [Estevez de Pablo et al., 1980; Schinzel, 2001; Moghe et al., 1981; Martin and Simpson, 1982; Taysi et al., 1982; Silengo et al., 1984; Beemer et al., 1985; Franco et al., 1991; Leichtman et al., 1993; Lo et al., 1993; Melis et al., 1998; Waggoner et al., 1999; Pallotta et al., 2001; Monica et al., 2007; Reddy et al., 2009]. We compiled a table of clinical features to determine the frequency of abnormalities in patients with deletions of chromosome 1 overlapping q21.3q23.3 (Table I) in order to determine possible genotype-phenotype correlations. Common features observed in our two siblings include blepharophimosis, everted nares, preauricular pits, widely spaced teeth, low-set ears, gingival hypertrophy, obstructive sleep apnea, hypoventilation syndrome with the need for supplemental oxygen at night, hypoplastic corpus callosum, left ventricle dilatation, increased lower extremity tone, feeding difficulty, and seizures. Arnold-Chiari Type I malformation, in Patient 2, has not been reported in other patients with similar deletions, perhaps because ascertainment was not attempted. The greatest limitation to the comparisons here are the uncertainties of genomic boundaries in prior reports. In addition, genotype-phenotype correlation may not be possible with so few patients, and deletions may disrupt regulation of adjacent, non-deleted genes.

There are 123 known genes that lie within the $6.33 \mathrm{Mb}$ genomic region and 18 are online Mendelian inheritance in man (OMIM) disease genes. Table II details the 18 OMIM disease genes, their clinical characteristics and inheritance. We examined those 18 genes for potential haploinsufficiency phenotypes. Of these 18, Lamin A/C haploinsufficiency ( $L M N A$ ) can give rise to the allelic disorders autosomal dominant Emery-Dreifuss muscular dystrophy (EDMD), limb-girdle muscular dystrophy type 1B, and dilated cardiomyopathy type 1A [Benedetti et al., 2007]. Patients with these disorders typically exhibit a combination of symptoms. Bonne et al. $[1999,2000]$ reported wide clinical variability for heterozygous loss of LMNA function, and EDMD patients may also exhibit contractures of the elbows and the Achilles tendons. Although there are certainly other potential reasons, we speculate that LMNA loss of function may be related to the Achilles and elbow contractures in our patients. We acknowledge in Patient 2 that Arnold-Chiari malformation should be taken into account with respect to contractures, but Arnold-Chiari malformation is not present in Patient 1. Given that cardiac pathology (cardiac conduction abnormalities and dilated cardiomyopathy) may arise in patients with $L M N A$ heterozygous loss of function [Benedetti et al., 2007], we sought formal cardiac evaluations for Patients 1 and 2. Those evaluations showed diminished biventricular systolic function and mild left 

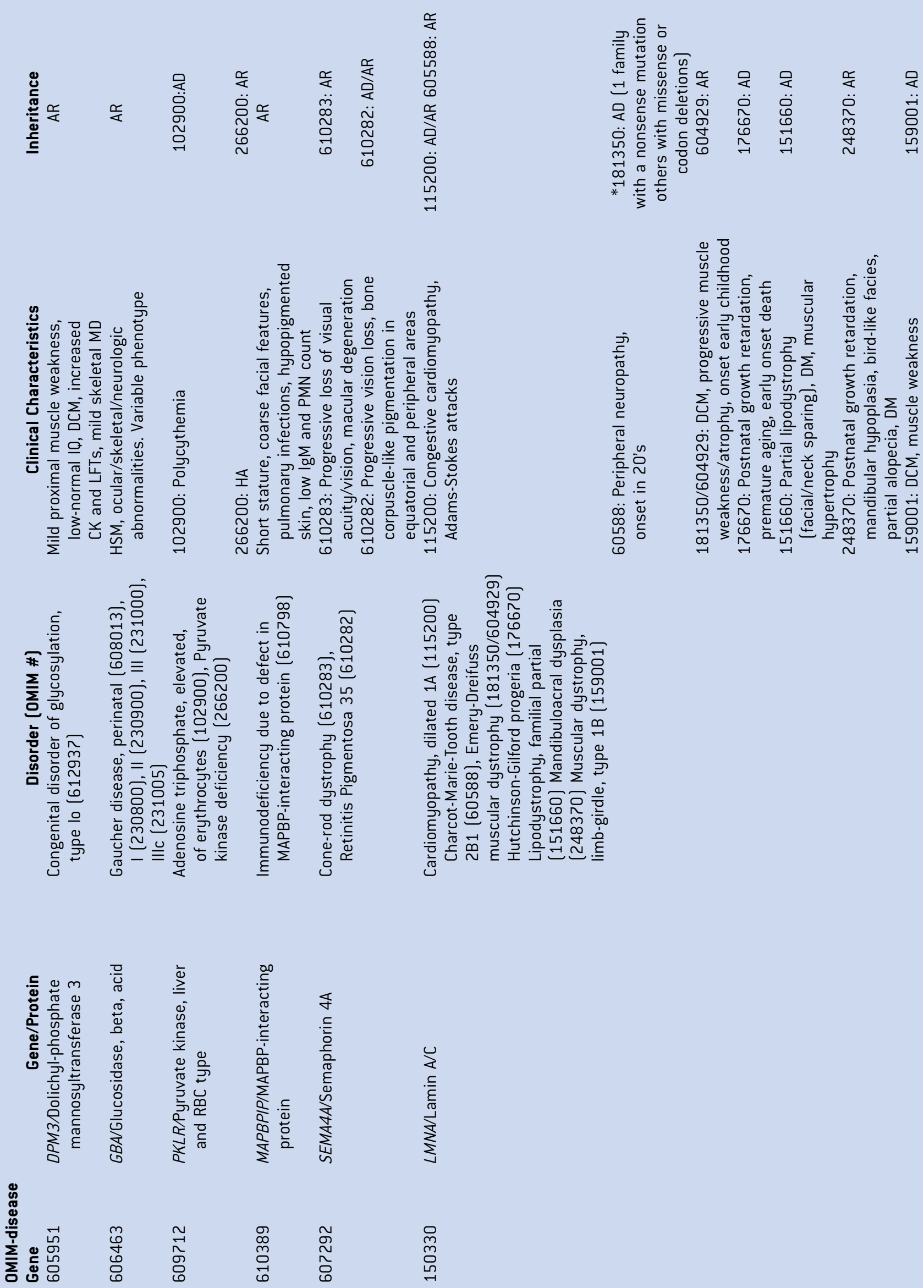


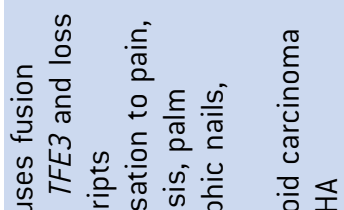

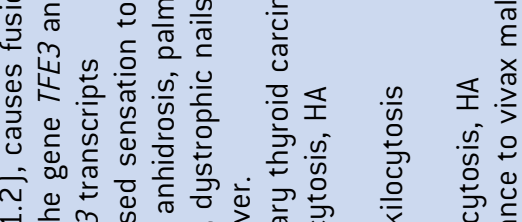

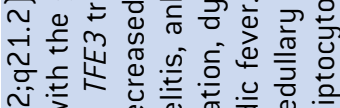

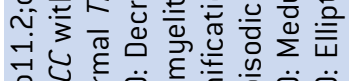
光㫕

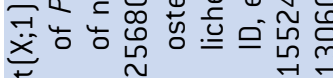

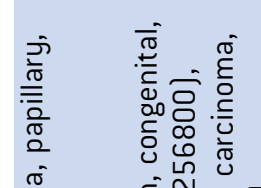

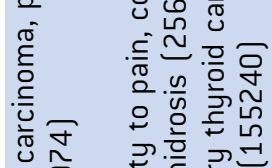

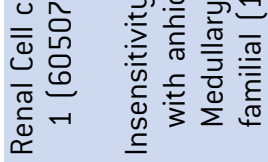

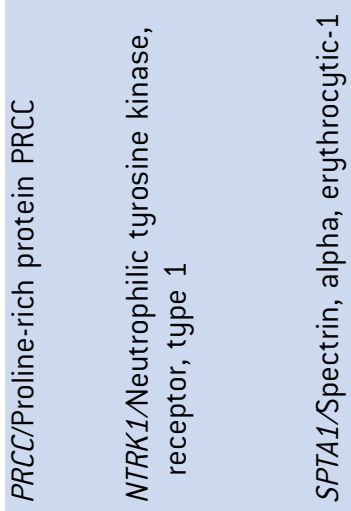

$\frac{\sqrt{\frac{\pi}{2}}}{\frac{\pi}{\pi}}$ 苞芯

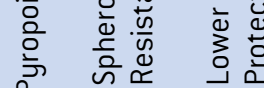
守

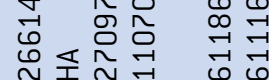

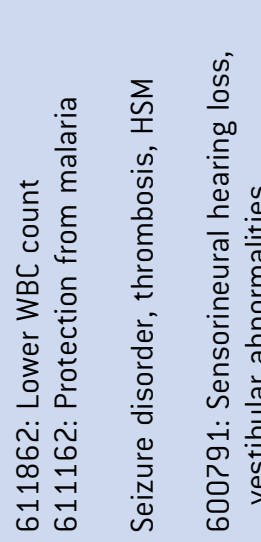

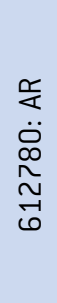

证

돈

厄ृ

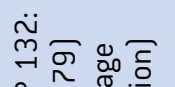

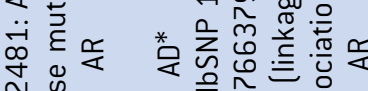

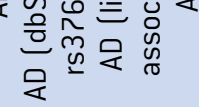

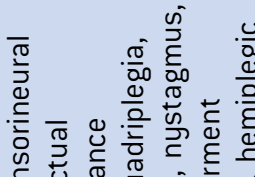

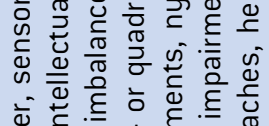

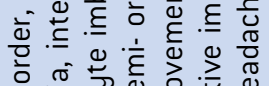

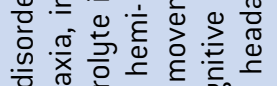

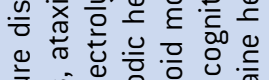

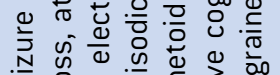

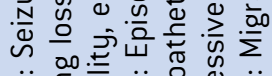

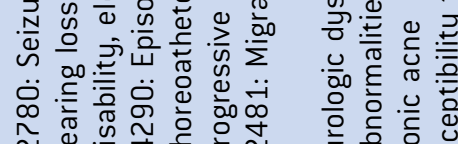

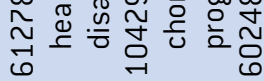

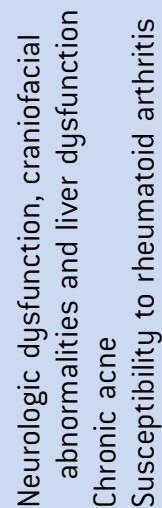

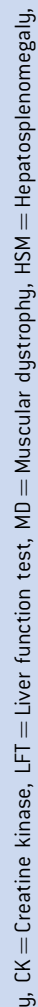

,

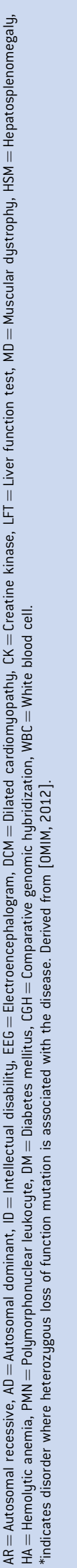


ventricular dilation in both and AV conduction abnormalities in Patient 2. Irrespective of whether haploinsufficiency for LMNA may also explain this cardiac pathology, it was ultimately the review of the phenotypes caused by heterozygous losses in the deleted interval that led to consideration of the potential for cardiac involvement. Haploinsufficiency for other genes in this interval are likely contributors to abnormal CNS development and function as well as craniofacial dysmorphisms.

For many years prior to the identification of the deletion in our patients, our differential diagnosis based on their clinical features included Blepharophimosis-ptosis-epicanthus inversus syndrome (BPES), 17q21 microdeletions, and the blepharophimosis-mental retardation (BMR) family of syndromes previously known as Ohdo syndrome [Ohdo et al., 1986; White et al., 2003; Verloes et al., 2006; Koolen et al., 2008; Beysen et al., 2009]. Evaluation of patients with BPES-like phenotypes or BMR spectrum should include array CGH because the distinctions between BMR types is not always clear. Recent work in the field of Ohdo syndrome/BMR syndromes showed mutations in $K A T 6 B$, a histone acetyltransferase encoded on chromosome 10q22, in the Say-Barber-Biesecker variant of Ohdo syndrome [Clayton-Smith et al., 2011]. Future work will help to define whether genes in the 1q21.3q23.3 interval reported here contribute to a fraction of uncharacterized BMR syndrome cases.

\section{REFERENCES}

Baldwin EL, Lee JY, Blake DM, Bunke BP, Alexander CR, Kogan AL, Ledbetter DH, Martin CL. 2008. Enhanced detection of clinically relevant genomic imbalances using a targeted plus whole genome oligonucleotide microarray. Genet Med 10:415-429.

Beemer FA, Klep-de Pater JM, Sepers GJ, Janssen B. 1985. Two cases of interstitial deletion of the long arm of chromosome 1: $\operatorname{del}(1)(\mathrm{q} 21 \mathrm{q} 25)$ and $\operatorname{del}(1)(q 41 q 43)$. Clin Genet 27:515-519.

Benedetti S, Menditto I, Degano M, Rodolico C, Merlini L, D’Amico A, Palmucci L, Berardinelli A, Pegoraro E, Trevisan CP, Morandi L, Moroni I, Galluzzi G, Bertini E, Toscano A, Olive M, Bonne G, Mari F, Caldara R, Fazio R, Mammi I, Carrera P, Toniolo D, Comi G, Quattrini A, Ferrari M, Previtali SC. 2007. Phenotypic clustering of lamin A/C mutations in neuromuscular patients. Neurology 69:1285-1292.

Beysen D, De Paepe A, De Baere E. 2009. FOXL2 mutations and genomic rearrangements in BPES. Hum Mutat 30:158-169.

Bonne G, Rffaele Di Barletta M, Varnous S, Becane HM, Hammouda EH, Merlini L, Muntoni F, Greenberg CR, Gary F, Urtizberea JA, Duboc D, Fardeau M, Toniolo D, Schwartz K. 1999. Mutations in the gene encoding lamin A/C cause autosomal dominant Emery-Dreifuss muscular dystrophy. Nat Genet 21:285-288.

Bonne G, Mercuri E, Muchir A, Urtizberea A, Becane HM, Recan D, Merlini L, Wehnert M, Boor R, Reuner U, Vorgerd M, Wicklein EM, Eymard B, Duboc D, Penisson-Besnier I, Cuisset JM, Ferrer X, Desguerre I, Lacombe D, Bushby K, Pollitt C, Toniolo D, Fardeau M, Schwartz K, Muntoni F. 2000. Clinical and molecular genetic spectrum of autosomal dominant Emery-Dreifuss muscular dystrophy due to mutations of the lamin A/C gene. Ann Neurol 2:170-180.

Clayton-Smith J, O'Sullivan J, Daly S, Bhaskar S, Day R, Anderson B, Voss AK, Thomas T, Biesecker LG, Smith P, Fryer A, Chandler KE, Kerr B, Tassabehji M, Lynch SA, Krajewska-Walasek M, McKee S, Smith J, Sweeney E, Mansour S, Mohammed S, Donnai D, Black G. 2011. Whole-exome-sequencing identifies mutations in histone acetyltrans- ferase gene KAT6B in individuals with the Say-Barber-Biesecker variant of Ohdo syndrome. Am J Hum Genet 89:675-681.

D’haene B, Nevado J, Pugeat M, Pierquin G, Lowry RB, Reardon W, Delicado A, Garcia-Minaur S, Palomares M, Courtens W, Stefanova M, Wallace S, Watkins W, Shelling AN, Wieczorek D, Veitia RA, De Paepe A, Lapunizina P, De Baere E. 2010. FOXL2 copy number changes in molecular pathogenesis of BPES: Unique cohort of 17 deletions. Hum Mutat 31:E1332-E1347.

Estevez de Pablo C, Garcia Sagredo JM, Ferro MT, Ferrando P, San Roman C. 1980. Interstitial deletion in the long arms of chromosome 1:46, XY,del(1)(pterq22:q25qter). J Med Genet 17:483-486.

Franco B, Lai LW, Patterson D, Ledbetter DH, Trask BJ, van den Engh G, Iannaccone S, Frances S, Patel PI, Lupski JR. 1991. Molecular characterization of a patient with $\operatorname{del}(1)(\mathrm{q} 23-\mathrm{q} 25)$. Hum Genet 87:269-277.

Kang S-H, Shaw C, Ou Z, Eng PA, Cooper L, Pursley AN, Sahoo T, Bacino CA, Chinault AC, Stankiewicz P, Patel A, Lupski JR, Cheung SW. 2010. Insertional translocation detected using FISH confirmation of arraycomparative genomic hybridization (aCGH) results. Am J Med Genet Part A 152A:1111-1126.

Koolen DA, Sharp AJ, Hurst JA, Firth HV, Knight SJL, Goldenberg A, Saugier-Veber P, Pfundt R, Vissers LELM, Destree A, Grisart B, Rooms L, Van der Aa N, Field M, Hackett A, Bell K, Nowaczyk MJM, Mancini GMS, Poddighe PJ, Schwartz CE, Rossi E, De Gregori M, Antonacci-Fulton LL, McLellan MD II, Garrett JM, Wiechert MA, Miner TL, Crosby S, Ciccone R, Willatt L, Rauch A, Zenker M, Aradhya S, Manning MA, Strom TM, Wagenstaller J, Krepischi-Santos AC, Vianna-Morgante AM, Rosenberg C, Price SM, Stewart H, Shaw-Smith C, Brunner HG, Wilkie AOM, Veltman JA, Zuffardi O, Eichler EE, de Vries BBA. 2008. Clinical and molecular delineation of the 17q21.31 microdeletion syndrome. J Med Genet 45:710-720.

Leichtman LG, Strum D, Brothman AR. 1993. Multiple craniofacial anomalies associated with an interstitial deletion of chromosome 1(q21q25). Am J Med Genet 45:677-678.

Lo LJ, Noordhoff MS, Huang CS, Chen CSH, Chen KT, Chen YR. 1993. Proximal deletion of the long arm of chromosome 1: [del(1)(q23-q25)]. Cleft Palate Craniofac J 30:586-589.

Martin AO, Simpson JL. 1982. Interstitial deletion 46,XY,del(1)(q23q25). Hum Genet 61:277.

Melis D, Perone L, Sperandeo MP, Sabbatino MS, Tuzzi MR, Romano A, Parenti G, Andria G. 1998. Mild phenotype associated with an interstitial deletion of the long arm of chromosome 1. J Med Genet 35:1047-1049.

Moghe M, Patel ZM, Peter JJ, Ambani LM. 1981. Cytogenetic studies in a selected group of mentally retarded children. Hum Genet 58:184187.

Monica MD, Lonardo F, Faravelli F, Pierluigi M, Luquetti DV, De Gregori M, Zuffardi O, Scarano G. 2007. A case of autism with an interstitial 1q deletion (1q23.3-24.2) and a de novo translocation of chromosomes 1q and 5q. Am J Med Genet Part A 143A:2733-2737.

Nowakowska BA, de Leeuw N, Ruivenkamp CAL, Sikkema-Raddatz B, Crolla JA, Thoelen R, Koopmans M, den Hollander N, van Haeringen A, van der Kevie-Kersemaekers AM, Pfundt R, Mieloo H, van Essen T, de Vries BBA, Green A, Reardon W, Fryns JP, Vermeesch JR. 2011. Parental insertional balanced translocations are an important cause of apparently de novo CNVs in patients with developmental anomalies. Eur J Hum Genet 20:166-170

Ohdo S, Madokoro H, Sonoda T, Hayakawa K. 1986. Mental retardation associated with congenital heart disease, blepharophimosis, blepharoptosis, and hypoplastic teeth. J Med Genet 23:242-244.

Online Mendelian Inheritance in Man, OMIM (TM). Johns Hopkins University, Baltimore, MD. MIM Number: 602483: 7/11/2012. World Wide Web URL: http://www.ncbi.nlm.nih.gov/omim/ 
Pallotta R, Dalpra L, Ehresmann T, Fusilli P. 2001. A patient defines the interstitial 1q deletion syndrome characterized by Antithrombin III deficiency. Am J Med Genet 104:282-286.

Reddy S, Dolzhanskaya N, Krogh J, Velinov M. 2009. A novel 1.4 Mb de novo microdeletion of chromosome 1q21.3 in a child with microcephaly, dysmorphic features and mental retardation. Eur J Med Genet 52: 443-445.

Schinzel A, Schmid W. 1980. Interstitial deletion of the long arm of chromosome 1, del(1)(q21q25) in a profoundly retarded 8-year-old girl with multiple anomalies. Clin Genet 18:305-313.

Schinzel A. 2001. Catalogue of unbalanced chromosomal aberrations in man. Berlin: Walter de Gruyter. p 44-46.

Silengo MC, Davi GF, Bianco R, Biagioli M, Guala A, Franceschini P, Novelli G. 1984. Interstitial deletion of chromosome 1(q23-q25). Report of a case. Clin Genet 25:549-552.
Taysi K, Sekhon GS, Hillman RE. 1982. A new syndrome of proximal deletion of the long arm of chromosome 1: 1q21-231q25. Am J Med Genet 13:423-430.

Verloes A, Bremond-Gignac D, Isidor B, David A, Baumann C, Leroy MA, Stevens R, Gillerot Y, Heron D, Heron B, Benzacken B, Lacombe D, Brunner H, Bitoun P. 2006. Blepharophimosis-mental retardation (BMR) syndromes: A proposed clinical classification of the so-called Ohdo syndrome, and delineation of two new BMR syndromes, one X-linked and one autosomal recessive. Am J Med Genet Part A 140A: 1285-1296.

Waggoner DJ, Ciske DJ, Dowton SB, Watson MS. 1999. Deletion of 1q in a patient with acrofacial dystosis. Am J Med Genet 82:301-304.

White SM, Ades LC, Amor D, Liebelt J, Bankier A, Baker E, Wilson M, Savarirayan R. 2003. Two further cases of Ohdo syndrome delineate the phenotypic variability of the condition. Clin Dysmorphol 12:109-113. 